\title{
PENDEKATAN STUDI ISLAM Sejarah Awal Perkenalan Islam Dengan Tasawuf
}

\author{
Miftahul Ulum \\ STAI Syaichona Moh. Cholil Bangkalan, Indonesia \\ Miftahul_ulum2001@yahoo.com
}

\begin{abstract}
Received: 30-03-2020
Revised: 19-06-2020

Accepted: 30-06-2020

\section{Islamic Study Approach: Early History of Introducing Islam with Sufism}

Abstract

Sufism is the most important religious heritage for Muslims who can bring it closer to the God. Therefore, Sufism and Islam cannot be separated. Although initially there was a debate about the origins of Sufism which many orientalists say came from outside Islam. However, then some Orientalists reviewed their opinions, one of which was R.A. Nicholson finally referred to Sufism to Islamic sources. And Rasullab is both a source and a prime example for Sufis based on the Qur'an and its Sunnah. In its development Sufism consists of four periods, namely: the period of the Prophet, Friends, Tabi'in and the spread of Sufism. The main points of the teachings are focused on moral Sufism, practice, and philosophy.
\end{abstract}

Keywords: Sufism, Islam, Sufi

\begin{abstract}
Abstrak
Tasawuf merupakan pusaka keagamaan terpenting bagi kaum muslimin yang bisa mengantarkannya untuk lebih dekat dengan Sang Kholik. Oleh karenanya, tasawuf dan Islam tidak dapat dipisahkan. Meski pada awalnya terdapat perdebatan mengenai asal usul tasawuf yang oleh para orientalis banyak disebutkan berasal dari luar Islam. Akan tetapi, kemudian sebagian orientalis meninjau kembali pendapat mereka, salah satunya yaitu R.A. Nicholson yang akhirnya merujuk tasawuf pada sumber Islam. Tujuan dari penelitian ini untuk mengetahui dan melacak sejarah perkembangan tasawuf tersebut, supaya tidak ada lagi perdebatan yang bisa memecah belah dan menggoyahkan keyakinan terkait sumber pertama lahirnya tasawuf. Penelitian ini menggunakan metode kualitatif dengan pendekatan historis. Hasil penelitiannya menunjukkan bahwa Tasawuf bersumber dari Islam itu sendiri dan Rasullah adalah sumber sekaligus contoh utama bagi kaum sufi yang berlandaskan pada Al-Qur'an dan Sunnahnya. Dalam perkembangannya tasawuf terdiri dari empat periode, yaitu: periode Rasulullah, Sahabat, Tabi'in dan penyebaran tasawuf. Adapun pokok ajarannya dititik beratkan pada tasawuf akhlaki, amali, dan falsafi.
\end{abstract}

Kata Kunci : Tasawuf, Islam, Sufi. 


\section{PENDAHULUAN}

- Kebanyakan kalangan muslim percaya bahwa salah satu aspek penting untuk mengetahui keuniversalan ajaran Islam adalah adanya dorongan untuk senantiasa mencari ilmu pengetahuan dimana saja dan kapan saja umat Islam berada ${ }^{1}$. Dengan adanya dorongan dari ayat-ayat al-Qur'an maupun dalam al-Hadits yang menganjurkan umat Islam agar mencari ilmu pengetahuan inilah yang menyebabkan lahirnya beberapa disiplin ilmu pengetahuan dalam Islam, dimana salah satu di antaranya adalah lahirnya ilmu tasawuf.

Tasawuf adalah cabang ilmu dalam Islam yang penerapannya menekankan pada pembersihan diri melalui pembentukan akhlak yang baik. ${ }^{3}$ Tasawuf memegang peranan penting dalam kehidupan rohani Islam, ${ }^{4}$ dengan kata lain bertasawuf itu adalah fitrah manusia dimana dapat membersihkan diri dari segala kesibukan duniawi yang bertujuan untuk pencapaian hakikat kesucian rohani yang sesungguhnya, karena sesungguhnya tujuan akhir manusia adalah mengikat lingkaran rohaninya dengan Allah SWT. Sebagaimna tujuan dari penciptaanya yang semata-mata untuk mengabdikan diri pada Sang Kholik ${ }^{5}$.

Mempelajari tasawuf merupakan solusi tepat dalam mengatasi krisis-krisis akibat modernisasi untuk melepaskan dahaga dan memperoleh kesegaran dalam mencari Tuhan. Intisari ajaran tasawuf adalah bertujuan memperoleh hubungan langsung dan disadari dengan Tuhan, sehingga seseorang merasa dengan kesadarannya itu ia berada di hadirat-Nya. Terdapat beberapa tujuan kenapa tasawuf perlu dikembangkan dan disosialisasikan kepada masyarakat, tujuan tersebut antara lain. Menyelamatkan kemanusiaan dari kebingungan dan kegelisahan yang mereka rasakan sebagai akibat kurangnya nilai-nilai spiritual, Memahami tentang aspek

\footnotetext{
${ }^{1}$ Achmad Zainal Arifin, "Defending Traditions, Countering Intolerant Ideologies: Re-Energizing the Role of Modin in Modern Java," Al-Jami'ah: Journal of Islamic Studies 55, no. 2 (15 Desember 2017): 265-92, https://doi.org/10.14421/ajis.2017.552.265-292; Fahruddin Faiz, "Sufisme-Persia Dan Pengaruhnya Terhadap Ekspresi Budaya Islam Nusantara,” ESENSLA: Jurnal Ilmu-Ilmu Ushuluddin 17, no. 1 (2016): 1-15.

2 Masykur Arif, "Sejarah Tasawuf dengan Pendekatan Arkeologi," 'Anil Islam: Jurnal Kebudayaan dan Ilmu Keislaman 9, no. 2 (2016): 353-359; Abdul Kadir Riyadi, "Abû Nasr Al-Sarrâj Dan Wacana Sufistik Lintas Disiplin Keilmuan," Teosofi: Jurnal Tasawuf dan Pemikiran Islam 4, no. 2 (15 September 2015): 285-308, https://doi.org/10.15642/teosofi.2014.4.2.285-308.

${ }^{3}$ M. Amin Abdullah, "Religion, Science, and Culture: An Integrated, Interconnected Paradigm of Science," Al-Jami'ab: Journal of Islamic Studies 52, no. 1 (8 Juni 2014): 175-203, https://doi.org/10.14421/ajis.2014.521.175203.

4 Miftahul Ulum dan Abd Wahid, "Fikih Organisasi (Reaktualisasi Sejarah Nahdlatul Ulama (NU) Di Indonesia)," Al-Insyirob: Jurnal Studi Keislaman 5, no. 2 (4 September 2019): 54-75, https://doi.org/10.35309/alinsyiroh.v5i2.3517.

5 Muhammad Anas Ma`arif, “Tasawuf Falsafi Dan Implikasinya Dalam Pendidikan Islam,” Vicratina: Jurnal Pendidikan Islam 3, no. 1 (13 September 2018), http:// riset.unisma.ac.id/index.php/fai/article/view/1026.
} 
Miftahul Ulum

asoteris islam, baik terhadap masyarakat Muslim maupun non Muslim, Menegaskan kembali bahwa aspek asoteris islam (tasawuf) adalah jantung ajaran islam. ${ }^{6}$

Namun, masih terdapat perdebatan yang menuai pro dan kontra terkait asal usul lahirnya tasawuf. Di satu sisi ada yang menyatakan bahwa tasawuf bersumber dari Islam tapi disisi lain menyatakan bersumber dari non Islam. Dan hal itu penulis temukan pada berbagai literatur. Bahkan, dalam buku paket Akidah Akhlak untuk kelas XI kurikulum 2013 yang diterbitkan oleh Kementerian Agama disebutkan bahwa terdapat beberapa pandangan tentang asal usul tasawuf, yaitu:

Sufisme berasal dari bahasa Arab suf, yaitu pakaian yang terbuat dari wol pada kaum asketen (yaitu orang yang hidupnya menjauhkan diri dari kemewahan dan kesenangan). Dunia Kristen, neo platonisme, pengaruh Persi dan India ikut menentukan paham tasawuf sebagai arah asketis-mistis dalam ajaran Islam ${ }^{7}$. Sufisme yaitu ajaran mistik yang dianut sekelompok kepercayaan di Timur terutama Persi dan India yang mengajarkan bahwa semua yang muncul di dunia ini sebagai sesuatu yang khayali (als idealish verschijnt), manusia sebagai pancaran (uitvloeisel) dari Tuhan selalu berusaha untuk kembali bersatu dengan Dia. Paham tasawuf terbentuk dari dua unsur, yaitu (1) Perasaan kebatinan yang ada pada sementara orang Islam sejak awal perkembangan Agama Islam,(2) Adat atau kebiasaan orang Islam baru yang bersumber dari agama-agama non-Islam dan berbagai paham mistik. Oleh karenanya paham tasawuf itu bukan ajaran Islam walaupun tidak sedikit mengandung unsur-unsur Ajaran Islam, dengan kata lain dalam Agama Islam tidak ada paham Tasawuf walaupun tidak sedikit jumah orang Islam yang menganutnya ${ }^{8}$.

Tasawuf dan sufi berasal dari kota Bashrah di negeri Irak. Dan karena suka mengenakan pakaian yang terbuat dari bulu domba (Shuuf), maka mereka disebut dengan Sufi. Soal hakikat Tasawuf, ia itu bukanlah ajaran Rasulullah dan bukan pula ilmu warisan dari Ali

\footnotetext{
${ }^{6}$ Danial Danial, "Menghadirkan Tasawuf Di Tengah Pluralisme Dan Ancaman Radikalisme," Analisis: jurnal $\begin{array}{llllll}\text { studi } & \text { keislaman } & 11, & \text { no. } & 1 & \text { (2014): }\end{array}$ https://ejournal.radenintan.ac.id/index.php/analisis/article/viewFile/149/110; Muzakkir, Hidup Sehat dan Bahagia dalam Perspektif Tasawuf, 2 ed. (Jakarta: Prenada Media Grup, 2019).

7 Totok Jumantoro dan Samsul Munir Amin, Kamus ilmu tasawuf (Wonosobo: Amzah, 2005); Abuddin Nata, Akblak tasawnf (Jakarta: Rajawali Pers, 2010).

8 Andi Eka Putra, “Tasawuf Dan Perubahan Sosial-Politik (suatu Pengantar Awal)," Jurnal TAPIs 8, no. 1 (2017): 62-72; Muhammad Muntahibun Nafis dan Muhammad Ainun Najib, "Pemikiran Sufistik Dan Toleransi Beragama KH. Sholeh Bahruddin Di Pesantren Ngalah Pasuruan," TEOSOFI: Jurnal Tasawnf Dan Pemikiran Islam 7, no. 2 (5 Desember 2017): 330-52, https://doi.org/10.15642/teosofi.2017.7.2.330-352; Muhammad Anas Maarif dkk., "Character Education Through Dhikr Tariqa Qadiriyya Naqhsabandiyya Al-Usmaniyya Indonesia," Hampstead Psychological Associates 24, no. 07 (2020): 9.
} 
bin Abi Thalib ra. Menurut Asy Syaikh Ihsan Ilahi Zhahir berkata": "Tatkala kita telusuri ajaran Sufi periode pertama dan terakbir, dan juga perkataan-perkataan mereka baik yang keluar dari lisan atau pun yang terdapat di dalam buku-buku terdabulu dan terkini mereka, maka sangat berbeda dengan ajaran Al Qur'an dan As Sunnah. Dan kita tidak pernah melihat asal usul ajaran Sufi ini di dalam sejarah pemimpin umat manusia Mubammad SAW, dan juga dalam sejarah para shababatnya yang mulia, serta makbluk-makbluk, piliban Allab Ta'ala di alam semesta ini. Babkan sebaliknya, kita melihat bahwa ajaran Sufi ini diambil dan diwarisi dari kerabiban Nashrani, Brabma Hindu, ibadab Yabudi dan Zubud Buddha”.

Berdasar pada kajian teori diatas. Maka penulis tertarik untuk mengkaji tentang Sejarah Awal perkenalan Islam dengan Tasawuf. Yang dalam hal ini dirumuskan dalam pengertian tasawuf, sejarah tasawuf, landasan lahirnya tasawuf, perkembangan tasawuf, pokokpokok ajaran tasawuf, serta kedudukan tasawuf dalam Islam.

\section{PENGERTIAN TASAWUF}

Tasawuf (Tasawuf) atau Sufisme berasal dari bahasa arab: تصوف yang berarti ilmu untuk mengetahui bagaimana cara menyucikan jiwa, menjernihan akhlaq, membangun dhahir dan batin, untuk memperoleh kebahagian yang abadi. ${ }^{10}$ Ada beberapa pendapat perihal etimologi dari kata tasawuf. Menurut Imam al-Ghozali, akar kata tasawuf berasal dari shuuf yang bermakna kain wol yang kasar. Istilah ini digunakan sebagai simbol kerendahan hati para sufi. Mereka serahkan kehidupannya untuk beribadah dan mendekatkan diri kepada Allah sehingga dalam dirinya terpatri sifat Qona'ah yang mendorongnya tidak lagi berhasrat untuk hidup mewah dan larut dalam permainan duniawi. ${ }^{11}$

Sejalan dengan pengertian tersebut, Syamsun Ni'am juga menuangkan beberapa rumusan akar kata tasawuf diantaranya yaitu kata shaff yang berarti saf atau baris, karena sufi selalu berada pada baris pertama dalam shalat. Juga kata shafa yang berarti bersih, karena hatinya selalu dihadapkan kehadirat Allah SWT. dan shuffah atau shuffat al-masjid yang berarti serambi masjid, yakni tempat yang didiami oleh para sahabat yang tidak punya tempat tinggal. Ia hanya menghabiskan dan mengabdikan hidupnya untuk berdakwah dan berjihad. Dan terakhir adalah shopos (bahasa Yunani) yang berarti hikmah (kebijaksanaan). ${ }^{12}$

\footnotetext{
9 Anwar Rosihon, Akblak Tasawnf, 10 ed. (Bandung: Pustaka Setia, 2010); Ahmad Ahmad, "Epistemologi Ilmu-Ilmu Tasawuf," Jurnal Ilmiah Ilmu Ushuluddin 14, no. 1 (2016): 59-66; Abdul Kadir Riyadi, Arkeologi tasawuf: melacak jejak pemikiran tasawuf dari Al-Mubasibi hingga tasawuf Nusantara (Yogyakarta, 2016).

10 Atjeh Abubakar, Tarekat Dalam Tasawuf (Kelantan: Pustakan Aman Press SDN, 1933).

11 Rosihon, Akblak Tasawuf.

12 Syamsun Ni'am, “Tasawuf Di Tengah Perubahan Sosial (studi Tentang Peran Tarekat Dalam Dinamika Sosial-Politik Di Indonesia)," harmoni 15, no. 2 (2016): 123-137; Syamsun Ni’am, Tasawuf Studies: Pengantar Belajar Tasawuf (Ar-Ruzz Media, 2014).
} 
Miftahul Ulum

Adapun pengertian tasawuf dari segi istilah, bergantung dari sudut pandang yang digunakan. Ada tiga sudut pandang yang biasa digunakan para ahli, yaitu: (1) Dari sudut pandang manusia sebagai makhluk terbatas, tasawuf didefinisikan sebagai upaya menyucikan diri dengan cara menjauhkan pengaruh kehidupan dunia. (2) Dari sudut pandang manusia sebagai makhluk yang berjuang, tasawuf merupakan upaya memperindah diri dengan akhlak yang bersumber dari ajaran agama dalam rangka mendekatkan diri kepada Allah SWT (3) dari sudut pandang manusia sebagai makhluk yang bertuhan, tasawuf merupakan kesadaran fitrah (ketuhanan) yang dapat mengarahkan jiwa agar tertuju kepada kegiatan-kegiatan yang dapat menghubungkan manusia dengan Tuhan. ${ }^{1314}$

Sementara Abu Muhammad FH dan Zainuri Siroj dalam Kamus Istilah Agama Islam, mendefinisikan tasawuf sebagai faham yang mengajarkan tentang cara menyucikan jiwa sesuci mungkin dan berusaha untuk mendekatkan diri kepada Allah, sehingga kehadiran-Nya senantiasa dirasakan secara sadar dalam kehidupan sehari-hari. ${ }^{15}$ Dari berbagai uraian pendapat di atas, dapat penulis simpulkan bahwa tasawuf merupakan sebuah upaya penyucian diri dari hal-hal yang dapat melalaikannya dari kewajiban dan tugas-tugasnya sebagai hamba Allah. Sehingga ia tak lagi diperbudak nasfu yang seringkali memalingkannya dalam mengigat penciptanya. Yang mana penyucian tersebut menyangkut lahiriyah dan batiniyah. Dengan demikian, segala bentuk tindakannya murni semata-mata tuk menggapai ridho-Nya ${ }^{16}$.

\section{SEJARAH LAHIRNYA TASAWUF}

Banyak pendapat yang pro dan kontra mengenai asal-usul ajaran tasawuf, apakah ia berasal dari luar atau dari dalam agama Islam sendiri. Adapun kaum orientalis, mereka berpendapat bahwa tasawuf Islam lahir dari kompilasi sumber-sumber asing di luar Islam, baik kristen, india, maupun yang lain. Salah satu orientalis yang fanatis yakni Prof. Duboir yang mengembalikan tasawuf Islam di masa pertumbuhannya pada tradisi mistis Kristen dan India. ${ }^{17}$ Nicholson ${ }^{18}$ menjelaskan bersikap fanatis dengan kebudayaannya dan memandang bahwa tasawuf Islam terpengaruh oleh tradisi mistisme kristen, terutama dalam hal kezuhudan

\footnotetext{
${ }^{13}$ Nata, Akblak tasawnf, 155.

14 Abuddin Nata, Akblak Tasawnf dan Karakter Mulia (Jakarta: PT Raja Grafindo Persada, 2013), 155.

15 Abu Muhammad FH, Zainuri Siroj, Kamus Istilah Agama Islam(KIAI) (Jakarta: PT. Albama, 2009), 312.

16 Miftahul Ulum, "Metodologi Studi Islam (Spiritualitas Dalam Pendidikan Islam Dalam Pandangan Syed Muhammad Naquib Al-Attas)," Al Iman: Jurnal Keislaman Dan Kemasyarakatan 4, no. 1 (22 Maret 2020): 1-21, http://ejournal.kopertais4.or.id/madura/index.php/aliman/article/view/3805.

17 Ia berkata: "Di masa pertumbuhan golongan wali dan kaum asketik (zāhid) dari kalangan muslim yang mengesampingkan duniawi, kami melihat seolah-olah sejarah rahib-rahib Kristen yang tinggal di berbagai biara dan gereja di willayah Syiria dan Mesir, serta sejarah biksu India yang tengah berrenkarnasi." Lihat Muhammad Fauqi Hajjaj, Tasawuf Islam \& Akblak (Jakarta: Amzah, 2013), 17.

${ }^{18}$ Reynold Alleyne Nicholson, The Mystics of Islam (Sacramento, CA: Murine Press, 2007).
} 
(asketisme). Bahkan ia mengatakan gerakan zuhud terinspirasi oleh idealisme Kristen. Namun, pendapatnya itu tidak di dukung oleh bukti dan dalil sehingga tidak berapa lama kemudian ia menarik kembali pendapatnya ${ }^{19}$. Dan pada akhirnya ia pun mengakui bahsawanya tasawuf Islam meskipun dalam pertumbuhan dan perkembangannya terpengaruh oleh kebudayaan umat-umat lain, akan tetapi tetap mempunyai keterkaitan secara internal dengan ajaran-ajaran Islam sendiri.

Banyak perbedaan pendapat mengenai kapan munculnya istilah sufi pertama kali. Menurut Abdul Qosim Abdul Karim bin Hawazin bin Abdul Malik bin Talha bin Muhammad al Qusyairi (tokoh sufi dari Iran 376-465 H), istilah "Tasawnf' telah dikenal sebelum tahun 200 H. Tetapi ajaran pokok yang selanjutnya merupakan inti tasawuf itu baru muncul secara lengkap pada abad ke 3 Hijriyah, Pada abad kedua Hijriyah itu belum dikenal adanya orangorang yang disebut sufi. Sementara itu dari data yang terungkap orang pertama yang mendapat gelar sufi adalah Abu Hasyim al-Kufi (wafat 150H/761M). ${ }^{20}$

Menurut Muchlis Sholihin istilah tasawuf pertama kali diperkenalkan oleh seorang tokoh bernama Abu Hisyam, seorang zahid dari Syiria (wafat pada tahun 780). Ia mendirikan lembaga kaum Sufi yang dinamakan taqiyah (sejenis padepokan sufi). ${ }^{21}$ Bertolak dari hal itu, Dr. Hamka sebagaimana dikutip dari Mustafa Zahri mengatakan bahwa timbulnya tasawuf dalam Islam bersamaan dengan kelahiran agama Islam itu sendiri, bertumbuh di dalam jiwa pendiri Islam itu sendiri yaitu Muhammad SAW disauk airnya dari Al-Qur'an itu sendiri. ${ }^{22}$

\section{LANDASAN LAHIRNYA TASAWUF}

Landasan Tasawuf yang paling utama adalah al-Quran dan hadist nabi. Di antara ayat-ayat dan hadist-hadist yang menunjukkan pola hidup kerohanian dalam Islam antara lain adalah:

QS. Al-hadid: 20

$$
\text { فتره مسفرا ثمّ يكون حطاما و في الاخرة عذاب شديد ومغفرة من الله ورضوان ومالحيوة الدنيا الديا لعب الا متاع الغرور }
$$

Artinya:

${ }^{19}$ Muhammad Fauqi Hajjaj, Tasawnf Islam dan akblak (Jakarta: Pusaka Amzah, 2011).

${ }^{20}$ Mulyadhi Kartanegara dan Achmad Ta’yudin, Menyelami lubuk tasawnf (Jakarta: Erlangga, 2006); Muhammad Afif Anshori, "Kontestasi Tasawuf Sunnî Dan Tasawuf Falsafî Di Nusantara," Teosofi: Jurnal Tasawuf Dan Pemikiran Islam 4, no. 2 (17 September 2015): 309-27, https://doi.org/10.15642/teosofi.2014.4.2.309-327.

${ }^{21}$ Sholihin M. Muchlis, Ilmu Akblaq dan Tasawwuf (Pamekasan: STAIN Pamekasan Press, 2009), 124.

22 Mustofa Zahri, Kunci Memabami Ilmu Tasawnf, Cet. 1 (Surabaya: Bina Ilmu, 1993), 130. 
Miftahul Ulum

"Ketabuilah oleh kamu bahwa kehidupan dunia itu hanyalah suatu permainan dan suatu yang melalaikan, perbiasan dan bermegah-megahan antara kamu serta berbangga-banggaan tentang banyaknya harta dan anak, seperti bujan yang tanam-tanamannya mengagumkan para petani, kemudian tanaman itu menjadi kering dan kamu lihat warnanya kuning dan kemudian menjadi hancur. Dan di akbirat nanti ada azab yang keras dan ampunan dari Allah serta keridhoanNya, dan kehidupan dunia ini tiada lain hanyalah kesenangan yang menipu" ( Al-Hadid:20)23

Ayat diatas mengilustrasikan bahwa kehidupan di dunia tidak ada yang kekal. Bahkan, gemerlap keindahan yang ditampakkannya pun bersifat semu karena kehidupan yang kekal itu adanya setelah mati tepatnya di akhirat. Dengan demikian, tidak sepantasnya hati kita terpikat dan terbuai dengan kesenangan sesaat yang tanpa disadari sering kali membuat kita lalai dan memalingkan diri tuk taat beribadah dan mendekatkan diri pada Allah. Dan kelak hanya ada dua kemungkinan yang akan kita terima sesuai dengan tabungan amal kita di dunia, yakni antara azab yang pedih atau ampunan dan keridhaan Allah.

Rasulullah SAW bersabda:

$$
\text { لا ينطق له العبد يتقرّب اليّ با النوا فل حتّي احبّه فاذا احبته كنت سمعه الذي يسمع به و بصره الذي يبصر به ولسانه الذي }
$$

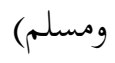

Artinya: "Senantiasalab seorang hamba itu mendekatkan kepada-Ku dengan amalan-amalan sunat, sebingga aku mencintainya. Maka apabila aku telah mencintainya, jadilah aku pendengarnya yang ia mendengar dengannya dan penglibatanny yang dengannya ia melibat dan lidahnya yang dia pakai untuk. berbicara dan tangannya yang dia pakai untuk mengepal dan kakinya yang dia pakai untuk berusaha. Maka, dengan-Ku lab dia mendengar, melibat, berbicara, berfikir, menggenggam, dan berjalan.”

Hadits tersebut memberi petunjuk bahwa antara manusia dan Tuhan bisa bersatu. Diri manusia bisa lebur dalam diri Tuhan, yang selanjutnya dikenal dengan istilah al-fana', yaitu fananya makhluk sebagai yang mencintai kepada diri Tuhan sebagai yang dicintai. ${ }^{24}$ Kedua dalil naqli di atas merupakan salah satu contoh dari ayat dan hadist yang menjadi dasar dan landasan bagi para pengamal ajaran tasawuf. Sekaligus Sebagai pendorong dan petunjuk untuk mendekatkan diri pada Allah dan Rasulnya. Selain itu, sirah nabi juga merupakan tumpuan perhatian mereka karena pada diri rasul terhimpun sifat-sifat yang menjadi suri tauladan. ${ }^{25}$

\section{PERKEMBANGAN TASAWUF}

\footnotetext{
${ }^{23}$ Hajjaj, Tasawuf Islam dan akblak, 27.

24 Nata, Akblak tasawuf, 157-58.

${ }^{25}$ Miftahul Ulum, "The Concept Of Maslahah By Al-Imam Malik And Al-Imam Al-Tufi," Veteran Law Review 2, no. 1 (2019): 58-76.
} 


\section{Periode I Masa Rasulullah saw. (13 sebelum Hijrah-11H)}

Tasawuf pada masa Rasulullah Muhammad SAW adalah sifat umum yang terdapat pada hampir seluruh sahabat-sahabat Nabi tanpa terkecuali. Bahkan kehidupan beliau sebelum menjadi Rasul telah dijadikan teladan utama. Sebab, beliau yang memberi dasar pertama tentang tasawuf yang didasarkan pada Al-Qur'an dan Hadist ${ }^{26}$.

Salah satu contohnya yakni setiap bulan Ramadhan Nabi tidak pernah absen untuk melakukan tahannuts dan khalwah di gua hira untuk mendapatkan hidayah dan bimbingan dari Allah SWT sehingga hati dan jiwa menjadi bersih dan terjaga, sampai akhirnya beliau didatangi malaikat Jibril a.s. untuk menyampaikan wahyu pertama dari Allah SWT. ${ }^{27}$

Berdasar pada aktifitas Rasulullah tersebut nampak bahwa penekanan ajaran tasawuf pada periode ini berupa haliyah-amaliyah yaitu amalan/ibadah keruhanian yang dilakukan Nabi saw. dalam hidupnya yang berupa tahannus, khalwah, perilaku zuhud, dan lain sebagainya.

\section{Periode II Masa Sahabat $(11 \mathrm{H}-40 \mathrm{H})$}

Di samping pola hidup dan kehidupan Rasulullah yang ideal itu menjadi suri tauladan bagi para sahabat. Kehidupan dan ucapan para sahabat juga merupakan sumber aktivitas kesufian tempat menimba ilmu para sufi. ${ }^{28}$ Dalam hidup bertasawuf para sahabat telah berusaha berbuat sesuai dengan tuntutan rasulullah, hidup mereka penuh dengan sifat-sifat kesederhanaan, wara', tawadhu dan zuhud, semata-mata mengharap ridho dari Allah SWT. Beberapa sahabat yang tergolong sufi di abad pertama, Khulafaurrasyidin, Abu Ubaidah bin Jarrah, Said bin Amr, dan lain-lain.

Menurut catatan sejarah, diantara sekalian sahabat Nabi yang pertama kali memfilsafatkan ibadah dan menjadikan ibadah sebagai satu tarekat yang khusus adalah Huzaifa bin Al-Yamani, salah seorang sahabat nabi yang mulia dan terhormat. Beliau yang pertama kali menyampaikan ilmu-ilmu yang kemudian kita kenal dengan "Tasawuf", dan beliau pulalah yang membuka jalan serta teori-teori untuk tasawuf itu. ${ }^{29}$

Penekanan ajaran tasawuf pada periode ini sama dengan periode sebelumnya yakni hidup zuhud, yang senantiasa berpegang teguh pada Al-Qur'an dan Sunnah. Adapun tokohtokohnya yaitu: Abu Bakar Ash-Shiddiq, Umar bin Khattab, Utsman bin 'Affan, 'Ali bin Abi Thalib, Abu 'Ubaidah, Ibn Al-Jarrah, Sa'id bin 'Amr, Abdullah bin Mas'ud, Abu Dzar al-

\footnotetext{
${ }^{26}$ Rosibon, Akblak Tasawuf.

27 Ni'am, Tasawnf Studies, 121.

28 Kevin W. Fogg, "Islam in Indonesia’s Foreign Policy, 1945-1949," Al-Jami'ah: Journal of Islamic Studies 53, no. 2 (10 Desember 2015): 303-35, https://doi.org/10.14421/ajis.2015.532.303-305.

29 Zahri, Kunci Memahami Ilmu Tasawuf, 150.
} 
Miftahul Ulum

Ghifari, Salim Maulana, Abu Hudzaifah, 'Abdullah bin 'Umar, Miqdad bin 'Aswad, Salman Al-Farisi, dan lain sebagainya. ${ }^{30}$

\section{Periode III Masa Tabi'in (41H-100H)}

Para sufi dari kalangan tabi'in adalah murid-murid dari para sahabat Nabi saw. Diantara tabi'in yang sering dianggap sebagai peletak dasar ajaran tasawuf adalah Hasan AlBashri yang merupakan murid terdekat dari Huzaifah bin Al-Yaman yang pandangannya berpegang teguh pada zuhud, raja' dan khauf. Selanjutnya yaitu Rabi'ah Al-Adawiyah yang pandangan tasawufnya dikenal dengan konsep cinta murni kepada Allah SWT. (mahabbah).

Selain mereka berdua tokoh sufi lain pada masa tabi'in ini antara lain: Ibrahim bin Adzham, Sufyaan bin sa'id Ats-Tsaury, Daud ath-Thai, Malik bin Dinar, Tsabit Al-Banani, Ayub As-Syakhtayani, Muhammad bin Wasi', Thaus, Rabi' bin Khaitsam, dan lain-lain. Dan di masa tabi'in ini pelajaran tasawuf sudah mulai diajarkan dalam bentuk disiplin ilmu. ${ }^{31}$ Disamping itu, penekanan ajarannya juga berupa konsepsi tentang zuhud, raja', khauf, dan mahabbah yang berpedoman pada Al-Qur'an, Sunnah, dan tradisi sahabat. ${ }^{32}$

\section{Periode IV Masa Penyebaran Tasawuf (100H-450H)}

Pada masa ini perkembangan tasawuf dibilang cukup pesat, ditandai dengan adanya segolongan ahli tasawuf yang mencoba menyelidiki inti ajaran tasawuf yang berkembang pada masa itu, sehingga mereka membaginya ke dalam tiga macam, yakni tasawuf yang berintikan ilmu jiwa, ilmu akhlaq dan Metafisika. Dan pada masa ini tasawuf sudah mulai mengembangkan sayapnya keluar tanah Arab, seperti Iran, India, Afrika, dan lain-lain. Yang ditandai dengan tumbuhnya tarekat-tarekat dan masuknya pengaruh filsafat dan syi'ah ke dalam konsepsi tasawuf. ${ }^{33}$

Di masa ini tokoh sufi yang muncul diantaranya adalah Ma'ruf al-Kharkhi, Abu Sulaiman Ad-Darani, Abul Faidh Dzun Nun bin Ibrahim Al-Mishri, Harits al-Muhasibi, Abul Hasan Sirri as-Siqti, dan lain-lain.

\section{POKOK-POKOK AJARAN TASAWUF}

\section{Tasawuf Akhlaki}

Sebagaimana namanya perhatian utama Tasawuf ini diarahkan tuk menjadikan manusia bersih jiwanya dalam rangka mencapai tujuan untuk mendekatkan diri dan

\footnotetext{
30 Ni'am, Tasawnf Studies, 134.

${ }^{31}$ Ni'am, Tasawuf Studies, 125.

${ }^{32} \mathrm{Ni}$ 'am, Tasawmuf Studies, 134.

33 Ibid., 126.
} 
beribadah kepada Allah ${ }^{34}$. Menurut pandangan kaum sufi manusia cenderung mengikuti hawa nafsu yang mendorongnya tuk menguasai dunia dan segala isinya, sehingga ia lupa dengan tujuan seorang hamba tuk menggapai ridha Allah. Akan tetapi, ia justru menjadikan kenikmatan hidup dunia sebagai tujuan utamanya. ${ }^{35}$

Tindakan manusia yang dikendalikan nafsu tersebut merupakan tabir penghalang bagi manusia tuk dekat dengan Tuhannya. Sebagai usaha menyingkap tabir yang menghalangi, ahli tasawuf membuat suatu sistem yang tersusun menjadi tiga tingkatan: takhalli, tahalli, dan tajalli. ${ }^{36}$

Takhalli berarti mengosongkan diri dari perangai yang tercela. Seperti menjaga diri dari perbuatan maksiat.

Tahalli berarti menghiasi diri dengan akhlak terpuji, dan

Tajalli berarti mengalami kenyataan ketuhanan. ${ }^{37}$ Pada tahap ini seorang sufi telah mencapai derajat ma'rifah sehingga semua perbuatannya (amalan-amalan) yang ia dilakukan semata-mata karena rasa cintanya pada sang kholik, tanpa mengharap pamrih berupa apapun seperti halnya surga.

Ajaran-ajaran para tokoh Sufi Sunni/Akhlaki menyangkut keseluruhan akhlak yang diajarkan dalam Al-Qur'an dan Hadits. Dari kedua sumber hukum dan sumber ajaran Islam itulah mereka menularkan ajaran-ajaran akhlak seperti Zuhud, taubat, tawakkal, sabar, mahabbah, ridha, dll. Ajaran dalam tasawuf ini sesuai dengan misi di utusnya Rasulullah yaitu untuk memperbaiki akhlak manusia. Yang mana ajaran-ajaran tasawuf tersebut telah dipraktekkan dalam kehidupan Rasulullah dan di lanjutkan oleh para sahabat beliau, misalnya seperti Abu Bakar Ash-Shiddiq yang terkenal dengan tawakkal dan sabar, Umar bin Khattab dikenal dengan keadilan dan kebijaksanaannya. ${ }^{38}$ Konsep penyucian jiwa ini banyak tertuang dalam Al-Qur'an seperti dalam QS. Al-a'la: 14-15, As-Syams: 9-10, 'Abasa: 3, dan lain sebagainya

\section{Tasawuf Amali}

Tasawuf ini menekankan pada amalan-amalan dan ibadah. Dan para penganutnya membagi ajaran agama kepada ilmu lahir dan ilmu batin, yaitu ajaran agama yang

\footnotetext{
${ }^{34}$ Muhammad Husnur Rofiq dan Prastio Surya, "Model Pembentukan Karakter Berbasis Tasawuf Akhlaqi," Ilmuna: Jurnal Studi Pendidikan Agama Islam 1, no. 2 (2019): 65-81, https://jurnal.stituwjombang.ac.id/index.php/ilmuna/article/view/109.

35 Musyrifah Marshush Sunanto, Sejarah Peradaban Islam Indonesia (Fakultas Ushuluddin dan Filsafat UIN, 2010), 207.

36 Ibid., 208.

${ }^{37}$ Team Guru Bina PAI Madrasah Aliyah, Aqidah Akblak MA kelas XI (t.tp: Akik Pusaka, t.t.), 3.

${ }^{38}$ Sholihin, Ilmu Akblaq dan Tasawnuf, 109.
} 
Miftahul Ulum

pengamalannya mengandung arti lahiriyah dan bathiniyah. Lahiriyah adalah amalan-amalan yang mengikuti aturan-aturan syari'ah, sedangkan bathiniyah mengikuti aturan-aturan ahli tasawuf. ${ }^{39}$

\section{Tasawuf Falsafi}

Tasawuf falsafi adalah tasawuf yang ajaran-ajarannya memadukan antara visi mistis dengan visi rasional. Tasawuf yang berawal dari zuhud kemudian pada perkembangannya bermuara pada filsafat, yang pada awalnya adalah aplikasi kepada perilaku terpuji kemudian berlanjut kepada teori. Pada fase ini para sufi mengadakan pengkajian yang lebih mendalam tentang kandungan ilmu tasawuf, sehingga kemudian tasawuf berkembang bukan hanya zuhud dalam arti yang sederhana, tetapi mendapat pengaruh luar seperti ajaran filsafat yunani, ajaran budaya timur dan lainnya yang kelihatannya memang seperti ajaran Islam, tetapi bila diteliti lebih lanjut terkadang bukan Islam. Sebagai contoh adalah adanya faham wahdatul wujud, yaitu faham tentang keesaan dan kesatuan wujud yang beranggapan bahwa yang ada secara hakiki hanyalah satu, yaitu Tuhan. Sedangkan wujud dari semua yang diciptakan Tuhan bukanlah wujud hakiki tetapi hanyalah bayangan ${ }^{40}$. Para sufi yang mengajarkan aliran ini adalah mereka yang terpengaruh dengan ajaran-ajaran filsafat. Salah satunya adalah Abu Yazid Al-Bustami yang mengajarkan Al-Ittibad, Al-Hallaj yang mengajarkan Hulul, dan lain sebagainya ${ }^{41}$

\section{KEDUDUKAN TASAWUF DALAM ISLAM}

Ajaran Tasawuf dalam Islam, memang tidak sama kedudukan hukumnya dengan rukun-rukun Iman dan rukun-rukun Islam yang sifatnya wajib, tetapi ajaran Tasawuf bersifat sunnat. Maka Ulama Tasawuf sering menamakan ajarannya dengan istilah "Fadailu al-A'mal" (amalan-amalan yang hukumnya lebih afdhal, tentu saja maksudnya amalan sunnat yang utama. Tasawuf merupakan pengontrol jiwa dan membersihkan manusia dari kotoran-kotoran dunia di dalam hati, melunakan hawa nafsu, sehingga rasa takwa hadir dari hati yang bersih dan selalu merasa dekat kepada Allah. Tujuan tasawuf itu menghendaki manusia harus menampilkan ucapan, perbuatan, pikiran, dan niat yang suci bersih, agar menjadi manusia yang berakhlak baik dan sifat yang terpuji, sehingga menjadi seorang hamba yang dicintai Allah SWT. Oleh karena itu, sifat-sifat yang demikian perlu dimiliki oleh seorang muslim.

\footnotetext{
39 Sunanto, Sejarah Peradaban, 214.

40 Annemarie Schimmel, Mystical Dimensions of Islam (Jakarta Selatan: Mizan, 2013); W.T. Stace, Mysticism and Philosophy (Textbook Publishers, 2003).

${ }^{41}$ Sholihin, Imu Akblaq dan Tasawwuf, 110.
} 
Maka dengan bertasawuf, seseorang akan bersikap tabah, sabar, dan mempunyai kekuatan iman dalam dirinya, sehingga tidak mudah terpengaruh atau tergoda oleh kehidupan dunia yang berlebihan dengan bersikap qona'ah, yaitu sabar dan tawakal, serta menerima apa yang telah diberikan Allah walaupun sedikit. Oleh karena itu tasawuf betul-betul mendapatkan perhatian yang lebih dalam ajaran Islam.

Bukankah kita ingin dekat dengan Allah sedekat-dekatnya, serta merasa dekat denganNya? Oleh karena harus ada penyucian diri dengan selalu berusaha membersihkan hati, supaya kita memperoleh jiwa yang tenteram dan menjadi orang yang bahagia hidup di dunia dan akhirat. Seperti halnya Rasulullah saw, beliau adalah pembesar dari seluruh ahli tasawuf yang berdaya upaya dengan sangat kepada kesucian hati serta menjauhi dari sifat-sifat hati yang jelek.

Roh sebelum masuk ke tubuh manusia memang suci, tetapi setelah bersatu dengan tubuh sering kali menjadi kotor karena digoda hawa nafsu tubuh. Agar bisa mendekatkan diri kepada Tuhan yang maha suci, roh manusia harus terlebih dahulu disucikan. Dan sufi-sufi besar telah merintis jalan penyucian jiwa itu yang dikenal dengan nama Thariqah, yakni jalan yang mempunyai maqamat atau stasiun-stasiun. Yang mana di stasiun inilah orang yang ingin menjadi sufi membersihkan diri dari kotoran-kotoran yang melekat dalam dirinya. ${ }^{42}$

Stasiun tersebut dimulai dengan taubah (tobat), kemudian naik ke tahap kedua yakni maqam zuhud, berlanjut lagi ke maqam fakir, kemudian maqam sabar, selanjutnya beranjak lagi pada maqam tawakkal, kemudian maqam Ridho, dan disusul lagi pada maqam Mahabbah. Di maqam mahabbah inilah cinta pada Allah telah memenuhi kalbu sufi sehingga Allah membalasnya dengan membuka tabir dari mata hatinya yang kemudian mengantarkannya pada tingkat ma'rifah. Namun, disini belum puas dan ia tetap ingin lebih mendekatkan diri lagi pada Allah dengan memperbanyak dzikir hingga ia sampailah pada tahap akhir perjalanannya yakni tingkat Fana', Baqa',dan Ittibad ${ }^{\text {t3 }}$. Jadi, jelaslah bahwa seorang hamba bisa dekat dengan Allah, yaitu dengan bertasawuf. Dengan demikian tasawuf memiliki Kedudukan yang penting dalam ajaran Islam, mengingat perannya yang luas biasa dalm mengkontribusikan nilai-nilai keislaman.

\footnotetext{
${ }^{42}$ Ris'an Rusli, Tasawuf dan tarekat: studi pemikiran dan pengalaman sufi (Jakarta: RajaGrafindo Persada, 2013), 45.

${ }^{43}$ Hasan M Syaroni, “Tasawuf Akhlaqi Dan Implikasinya Dalam Pendidikan Agama Islam," Urwatul Wutsqo 5, no. 2 (2016).
} 
Miftahul Ulum

\section{KESIMPULAN}

Tasawuf merupakan sebuah upaya penyucian diri dari hal-hal yang dapat melalaikannya dari kewajiban dan tugas-tugasnya sebagai hamba Allah. Sehingga ia tak lagi diperbudak nasfu yang seringkali memalingkannya dalam mengigat penciptanya. Yang mana penyucian tersebut menyangkut lahiriyah dan batiniyah. Dengan demikian, segala bentuk tindakannya murni semata-mata tuk menggapai ridho-Nya.

Timbulnya tasawuf dalam Islam bersamaan dengan kelahiran agama Islam itu sendiri, bertumbuh di dalam jiwa pendiri Islam itu sendiri yaitu Muhammad SAW disauk airnya dari Al-Qur'an itu sendiri. Karenya, landasan lahirnya tasawuf adalah Al-Qur'an dan Hadits Nabi. Dalam perkembangannya tasawuf terdiri dari empat periode, yaitu: periode Rasulullah, Sahabat, Tabi'in dan penyebaran tasawuf. Sedangkan pokok ajarannya dititik beratkan pada tasawuf akhlaki, amali, dan falsafi. Kedudukan hukum Tasawuf tidak sama dengan rukunrukun Iman dan rukun-rukun Islam yang sifatnya wajib, tetapi ajaran Tasawuf bersifat sunnah. Karena Tasawuf merupakan pengontrol jiwa yang bisa membersihkan manusia dari kejahatan dalam hatinya, melunakkan hawa nafsu yang semakin menjadi raja, sehingga rasa takwa hadir dari hati yang bersih dan selalu merasa dekat kepada Allah yang menciptakan manusia. Untuk bisa dekat dan mengenal Tuhannya, seorang hamba harus berupaya tuk menyucikan dirinya terlebih dahulu dengan melalui beberapa tahapan. Dengan upaya-upaya tersebut diharapkan manusia bisa menemukan jalan terang untuk kembali kepada TuhanNya. Salah satu yang bisa dilakukan manusia untuk lebih mendekatkan diri dengan Tuhannya yaitu dengan belajar Tasawuf ini. Dan dengan adanya artikel ini maka penulis berharap akan memberikan banyak manfaat kepada yang membaca maupun kepada yang menulis. Amien.

\section{REFERENSI}

Abdullah, M. Amin. "Religion, Science, and Culture: An Integrated, Interconnected Paradigm of Science." Al-Jami'ah: Journal of Islamic Studies 52, no. 1 (8 Juni 2014): 175-203. https://doi.org/10.14421/ajis.2014.521.175-203.

Abubakar, Atjeh. Tarekat Dalam Tasawnf. Kelantan: Pustakan Aman Press SDN, 1933.

Ahmad, Ahmad. "Epistemologi Ilmu-Ilmu Tasawuf." Jurnal Ilmiah Ilmu Usbuluddin 14, no. 1 (2016): 59-66.

Annemarie Schimmel. Mystical Dimensions of Islam. Jakarta Selatan: Mizan, 2013.

Anshori, Muhammad Afif. "Kontestasi Tasawuf Sunnî Dan Tasawuf Falsafî Di Nusantara." Teosofi: Jurnal Tasawnf Dan Pemikiran Islam 4, no. 2 (17 September 2015): 309-27. https://doi.org/10.15642/teosofi.2014.4.2.309-327. 
Arif, Masykur. "Sejarah Tasawuf dengan Pendekatan Arkeologi." 'Anil Islam: Jurnal Kebudayaan dan Ilmu Keislaman 9, no. 2 (2016): 353-359.

Arifin, Achmad Zainal. "Defending Traditions, Countering Intolerant Ideologies: ReEnergizing the Role of Modin in Modern Java." Al-Jami'ab: Journal of Islamic Studies 55, no. 2 (15 Desember 2017): 265-92. https://doi.org/10.14421/ajis.2017.552.265-292.

Danial, Danial. "Menghadirkan Tasawuf Di Tengah Pluralisme Dan Ancaman Radikalisme." Analisis: jurnal studi keislaman 11, no. 1 (2014): 91-108. https://ejournal.radenintan.ac.id/index.php/analisis/article/viewFile/149/110.

Faiz, Fahruddin. "Sufisme-Persia Dan Pengaruhnya Terhadap Ekspresi Budaya Islam Nusantara.” ESENSLA: Jurnal Ilmu-Ilmu Ushuluddin 17, no. 1 (2016): 1-15.

Fogg, Kevin W. "Islam in Indonesia's Foreign Policy, 1945-1949.” Al-Jami'ab: Journal of Islamic Studies 53, no. 2 (10 Desember 2015): 303-35. https://doi.org/10.14421/ajis.2015.532.303-305.

Hajjaj, Muhammad Fauqi. Tasawnf Islam dan akhlak. Jakarta: Pusaka Amzah, 2011.

Jumantoro, Totok, dan Samsul Munir Amin. Kamus ilmu tasawuf. Wonosobo: Amzah, 2005.

Kartanegara, Mulyadhi, dan Achmad Ta'yudin. Menyelami lubuk tasawuf. Jakarta: Erlangga, 2006.

M. Muchlis, Sholihin. Imu Akblaq dan Tasammuf. Pamekasan: STAIN Pamekasan Press, 2009.

M Syaroni, Hasan. "Tasawuf Akhlaqi Dan Implikasinya Dalam Pendidikan Agama Islam." Urwatul Wutsqo 5, no. 2 (2016).

Ma`arif, Muhammad Anas. "Tasawuf Falsafi Dan Implikasinya Dalam Pendidikan Islam." Vicratina: Jurnal Pendidikan Islam 3, no. 1 (13 September 2018). http://riset.unisma.ac.id/index.php/fai/article/view/1026.

Maarif, Muhammad Anas, Muhammad Mujtaba Mitra Zuana, Siti Maryam Munjiat, Ibnu Rusydi, Ali Miftakhu Rosyad, dan Lu'lu’il Maknuun. "Character Education Through Dhikr Tariqa Qadiriyya Naqhsabandiyya Al-Usmaniyya Indonesia." Hampstead Psychological Associates 24, no. 07 (2020): 9.

Muzakkir. Hidup Sehat dan Bahagia dalam Perspektif Tasawnf. 2 ed. Jakarta: Prenada Media Grup, 2019.

Nafis, Muhammad Muntahibun, dan Muhammad Ainun Najib. "Pemikiran Sufistik Dan Toleransi Beragama KH. Sholeh Bahruddin Di Pesantren Ngalah Pasuruan.” TEOSOFI: Jurnal Tasawuf Dan Pemikiran Islam 7, no. 2 (5 Desember 2017): 330-52. https://doi.org/10.15642/teosofi.2017.7.2.330-352. 
Miftahul Ulum

Nata, Abuddin. Akblak tasawnf. Jakarta: Rajawali Pers, 2010.

Ni’am, Syamsun. “Tasawuf Di Tengah Perubahan Sosial (studi Tentang Peran Tarekat Dalam Dinamika Sosial-Politik Di Indonesia).” harmoni 15, no. 2 (2016): 123-137.

Ni'am, Syamsun. Tasawnf Studies: Pengantar Belajar Tasawnf. Ar-Ruzz Media, 2014.

Nicholson, Reynold Alleyne. The Mystics of Islam. Sacramento, CA: Murine Press, 2007.

Putra, Andi Eka. "Tasawuf Dan Perubahan Sosial-Politik (suatu Pengantar Awal)." Jurnal TAPIs 8, no. 1 (2017): 62-72.

Riyadi, Abdul Kadir. "Abû Nasr Al-Sarrâj Dan Wacana Sufistik Lintas Disiplin Keilmuan.” Teosofi: Jurnal Tasawuf dan Pemikiran Islam 4, no. 2 (15 September 2015): 285-308. https://doi.org/10.15642/teosofi.2014.4.2.285-308.

- Arkeologi tasawnf: melacak jejak pemikiran tasawnf dari Al-Mubasibi bingga tasawnf Nusantara. Yogyakarta, 2016.

Rofiq, Muhammad Husnur, dan Prastio Surya. "Model Pembentukan Karakter Berbasis Tasawuf Akhlaqi." Ilmuna: Jurnal Studi Pendidikan Agama Islam 1, no. 2 (2019): 65-81. https://jurnal.stituwjombang.ac.id/index.php/ilmuna/article/view/109.

Rosihon, Anwar. Akblak Tasawnf. 10 ed. Bandung: Pustaka Setia, 2010.

Rusli, Ris'an. Tasawuf dan tarekat: studi pemikiran dan pengalaman sufi. Jakarta: RajaGrafindo Persada, 2013.

Stace, W.T. Mysticism and Philosophy. Textbook Publishers, 2003.

Sunanto, Musyrifah Marshush. Sejarah Peradaban Islam Indonesia. Fakultas Ushuluddin dan Filsafat UIN, 2010.

Ulum, Miftahul. "Metodologi Studi Islam (Spiritualitas Dalam Pendidikan Islam Dalam Pandangan Syed Muhammad Naquib Al-Attas)." Al Iman: Jurnal Keislaman Dan Kemasyarakatan 4, no. 1 (22 Maret 2020): 1-21. http://ejournal.kopertais4.or.id/madura/index.php/aliman/article/view/3805.

—. "The Concept Of Maslahah By Al-Imam Malik And Al-Imam Al-Tufi." Veteran Law Review 2, no. 1 (2019): 58-76.

Ulum, Miftahul, dan Abd Wahid. "Fikih Organisasi (Reaktualisasi Sejarah Nahdlatul Ulama (NU) Di Indonesia)." Al-Insyiroh: Jurnal Studi Keislaman 5, no. 2 (4 September 2019): 54-75. https://doi.org/10.35309/alinsyiroh.v5i2.3517.

Zahri, Mustofa. Kunci Memahami Ilmu Tasawuf. Cet. 1. Surabaya: Bina Ilmu, 1993. 